\title{
Potentiometric Studies of Binary Complexes of Transition Metal ions with Lauric Acid
}

\author{
GOVINDARAJAN KAVITHA*, PARASURAMAN VIJAYAROHINI, \\ and SUNKUBANGARU SUDARSAN ALWAR
}

Department of Chemistry, D. G. Vaishnav College, University of Madras, Chennai, Tamil Nadu.

*Corresponding author E-mail: kavitha.rajsekhar@gmail.com

http://dx.doi.org/10.13005/ojc/340564

(Received: April 05, 2018; Accepted: August 15, 2018)

\begin{abstract}
The potentials of binary complexes of the Lauric acid ligand with various biologically vital divalent metal ions such as $\mathrm{Mn}(\mathrm{II}), \mathrm{Co}(\mathrm{II}), \mathrm{Ni}(\mathrm{II}), \mathrm{Cu}(\mathrm{II})$ and $\mathrm{Zn}(\mathrm{II})$ have been studied in 50\% DMSOwater mixture at constant ionic strength by Bjerrum method. Hydrogen ion concentrations were measured and the formation of binary complexes was inferred from the corresponding potentiometric $\mathrm{pH}$-titration curves. The metal to ligand mole ratio was maintained at $1: 5$ to facilitate the maximum number of ligands to the metal ion. The dissociation constant has been determined by the half-integral method and pointwise method and were found in good agreement with each other. The Metal-Lauric acid stability constants have been calculated and compared with the results.
\end{abstract}

Keywords: DMSO-water mixture, $\mathrm{pH}$-metric method, Stability constant.

\section{INTRODUCTION}

Studies on binary complexes of vital biological ligands in aqueous and aqueous-organic media have received reasonable attention in recent years. The nonaqueous and aqueous-organic solvents are used instead of water due to their wide range of applications. The current work is significant for understanding the role of the aqueous-organic solvent medium for complex formation. This part of the research work gives an insight about ion-solvent interaction and the interaction among the solvents. Dimethyl sulfoxide(DMSO) is well known polar aprotic solvent. Aqueous-DMSO, binary solvent medium is used as a cryoprotective agent. In the aqueous-DMSO mixture, the water structure is enhanced, the water from the coordination sphere of metal ions is removed, and they are made more approachable towards the ligands resulting in the increased stability of the complexes. But the competing behaviour of DMSO as a coordinating solvent may reduce the stability of the complex. Hence the increased and decreased stability of the complexes may be attributed to the structure forming and competing for the behaviour of $\mathrm{DMSO}^{1}$.

Lauric acid, dodecanoic acid, is a saturated fatty acid present in coconut milk and coconut oil2. It is

This is an Open Access article licensed under a Creative Commons Attribution-Non Commercial-Share Alike 4.0 International License (https://creativecommons.org/licenses/by-nc-sa/4.0/), which permits unrestricted Non Commercial use, distribution and reproduction in any medium, provided the original work is properly cited. 
widely used in the synthesis of soaps and cosmetics. Using the freezing-point depression method, the molecular weight of chemical compounds could be determined. Lauric acid is metabolized in the human body, into monolaurin which has significant antifungal and antimicrobial properties ${ }^{3}$. It destroys the microorganisms by disrupting their lipid membranes.

The essential metals such as manganese, Cobalt, Nickel, Copper and Zinc play an important role in biological processes. Cobalt is at the active center of coenzymes called cobalamin. Nickel is present in the enzyme, urease, which is found in the wide range of plant species. Copper is found to have antibacterial properties.

Hence, potentiometric studies of Lauric acid with selective transition metal ions have been carried out. In the present study, the dissociation constant, stability constants of lauric acid with the metal ions have been reported in aqueous- DMSO medium. The binary complexes are more suitable for the transport of metals in bio fuels due to their increased stability and the availability of metals would be enhanced in biological systems because of their lower stability.

Comprehensive research work has been carried out to have a quantitative approach in the field of complexation studies. A lot of literature survey ${ }^{4-9}$ has been carried out in this field still it is observed that little information is available about the protonligand constant ${ }^{10}$ of lauric acid in methanol-water and ethanol-water medium and the stability constants of the ligand with metal ions are not available.

\section{MATERIALS AND METHODS}

All chemicals used were of the analar grade. The metal salt solution, ligand solutions were prepared using deionized water and standardized by standard volumetric methods. The $\mathrm{pH}$ of the titrating mixture has been measured using a combined glass electrode attached to a Systronics microprocessorbased $\mathrm{pH}$ meter (QJ-666B) with accuracy \pm 0.01 . The calibration of $\mathrm{pH}$ meter has been carried out with suitable buffers. 50\% v/v DMSO-water medium was used. A measured quantity of potassium nitrate solution was added to maintain $0.1 \mathrm{M}$ ionic strength. The concentrations of lauric acid and metal ions solutions used were $20 \times 10^{-4} \mathrm{~mol} \mathrm{dm}^{-3}$, and $4 \times 10^{-4}$ $\mathrm{mol} \mathrm{dm}{ }^{-3}$. The three solution mixtures of volume 25 $\mathrm{mL}$ were prepared by taking the following solutions: (a) Free $\mathrm{HNO}_{3}$ (b) $\mathrm{HNO}_{3}$ + ligand (c) $\mathrm{HNO}_{3}$ + ligand + metal ion solution respectively.

Above three solution mixtures were titrated against standardized sodium hydroxide (0.098 M). The $\mathrm{pH}$ reading was observed after the addition of aliquots of alkali in all the cases. The recorded $\mathrm{pH}$ was plotted against the volume of sodium hydroxide. The acid curve, ligand curve and metal complex titration curve (Fig.1) were obtained. In the present work, Calvin-Bjerrum method, as modified by Rossotti-Rossotti1 ${ }^{11}$ was used, as the method is simple and reliable.

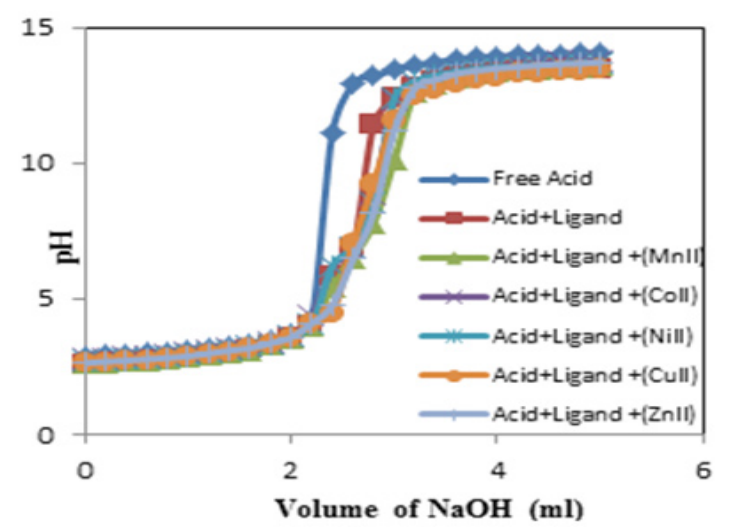

Fig. 1. pH-metric curves of free acid+ligand+ metalions $\mathrm{Mn}$ (II), $\mathrm{Co}(\mathrm{II}), \mathrm{Ni}(\mathrm{II}), \mathrm{Cu}$ (II) and $\mathrm{Zn}$ (II) in $50 \%(v / v)$ DMSO-50\% (v/v)water system

\section{RESULTS}

From the acid and ligand curves, the formation number, $\mathrm{nA}$ (average number of protons associated with the ligand) was calculated at different $\mathrm{pH}$ values. Using the Irving-Rossotti expression, the proton-ligand formation number, nA was estimated(Table 1).

$n_{A}=\frac{\gamma-\left(E^{\circ}+N\right)\left(V_{2}-V_{1}\right)}{\left(V^{\circ}+V_{1}\right) T^{\circ}{ }_{L}}$

Where $\gamma$ denotes number of replaceable protons, $\mathrm{E}^{\circ}, \mathrm{N}, \mathrm{T}^{\circ}{ }_{\mathrm{L}}$ are the concentration of acid and sodium hydroxide $(0.098 \mathrm{M})$ and the ligand respectively. $\mathrm{V}^{\circ}$ is the initial volume of the reaction mixture. $T$ he data of $\mathrm{nA}$ obtained at various $\mathrm{pH}$ values along the horizontal difference $\left(\mathrm{V}_{2}-\mathrm{V}_{1}\right)$ for representative systems. The dissociation equilibrium of the ligand can be shown as 
$\mathrm{HL} \rightleftharpoons \mathrm{H}++\mathrm{L}-$

The $\mathrm{pK}$ values of ligand from the formation numbers were determined using pointwise calculations. It is also estimated by the half-integral

Table 1: Pointwise method for calculation of pK in $\mathbf{5 0 \% ( v / v ) ~ D M S O - 5 0 \% ( v / v ) w a t e r ~}$ systemProton-ligand dissociation constant of Lauric acid at $27^{\circ} \mathrm{C}$ in $50 \%(\mathrm{v} / \mathrm{v})$ DMSO$\mathbf{5 0} \%(\mathrm{v} / \mathrm{v})$ water system

\begin{tabular}{ccccc}
\hline $\mathrm{pH}$ & $\mathrm{V} 1$ & $\mathrm{~V} 2$ & $\Delta \mathrm{V}=\mathrm{V} 2-\mathrm{V} 1$ & $\mathrm{nA}$ \\
\hline 5.6 & 2.249 & 2.388 & 0.319 & 0.7246 \\
5.8 & 2.251 & 2.410 & 0.159 & 0.6849 \\
6.0 & 2.262 & 2.442 & 0.180 & 0.6435 \\
6.2 & 2.266 & 2.482 & 0.216 & 0.5722 \\
6.4 & 2.270 & 2.524 & 0.254 & 0.4971 \\
6.6 & 2.276 & 2.556 & 0.280 & 0.4456 \\
6.8 & 2.282 & 2.582 & 0.300 & 0.4062 \\
7.0 & 2.289 & 2.602 & 0.325 & 0.3569 \\
7.2 & 2.294 & 2.619 & 0.327 & 0.3530 \\
\hline
\end{tabular}

method, by noting the corresponding $\mathrm{pH}$ for $\mathrm{nA}=$ 0.5 from proton-ligand formation curves $\mathrm{nA}$ versus $\mathrm{pH}$ (Fig. 2). The accurate value of pK which is determined by pointwise calculations is found to be almost the same as the value calculated by the half-integral method (Table 2).

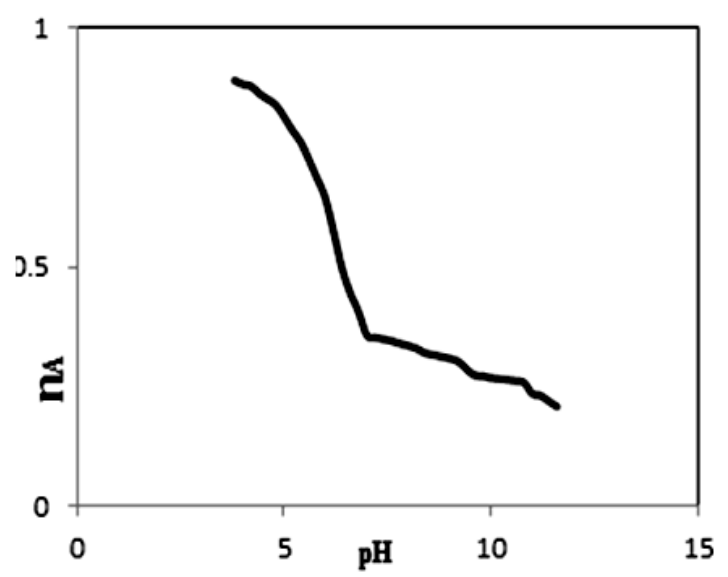

Fig. 2. Half integral method for determining pKof Lauric acid in $50 \%(\mathrm{v} / \mathrm{v})$ DMSO-50\%(v/v) water system

Table 2: pK values of Lauric acid

Ratio of DMSO - water mixture

pK(Half integral method) $\quad \mathrm{pK}$ (pointwise calculation method)

50\%(v/v) DMSO-50\%(v/v)water system

The increase in $\mathrm{pK}$ values in the binary solvent medium than pure water shows that DMSO plays a significant role to increase the basicity. The solvation effect and the bulk solvent structure might have been influenced by the dissociation of the ligand. From the metal complex titration curves. The average number of metal ions associated with the ligand (n) for different $\mathrm{pH}$ values have been calculated. The stability constants of metal complexes were obtained by the half-integral method. The $n$ values have been calculated by using the expression.

$n=\frac{\left(E^{\circ}+N\right)\left(V_{3}-V_{2}\right)}{\left(V^{\circ}+V_{2)}\right) T^{\circ}{ }_{m}}$

Where $\mathrm{N}, \mathrm{E}^{\circ}, \mathrm{V}^{\circ}$, and $\mathrm{V}_{2}$, have the similar importance as that of equation (1). $V_{3}$ is the volume of alkali added and $\mathrm{T}^{\circ} \mathrm{m}$ is the concentration of the metal ion.

The metal-ligand stability constants of various complexes have been determined using $n$ values(Fig. 3) and were tabulated. (Table 3).

$6.38 \quad 6.44$
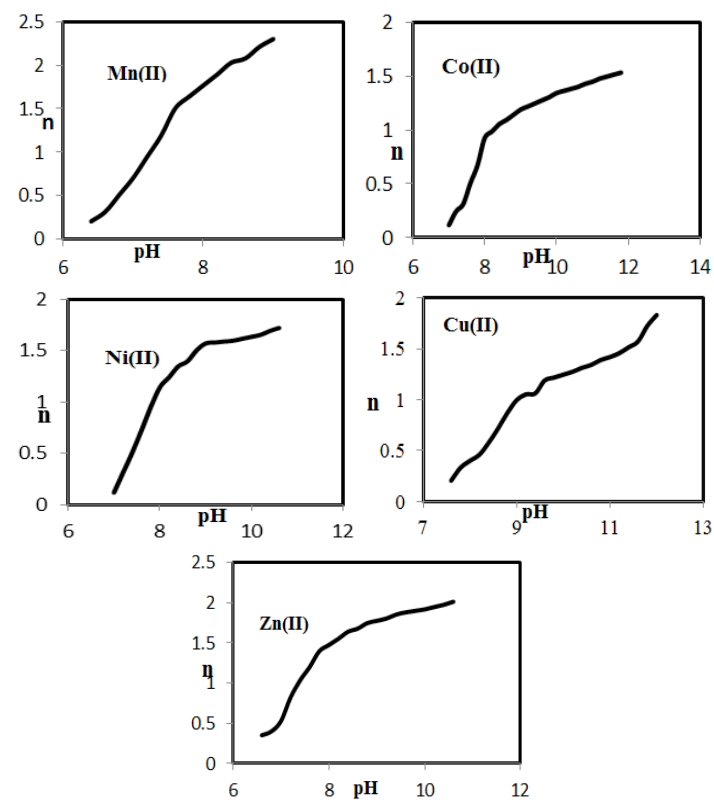

Fig. 3. Plot of $\mathrm{n}$ Vs pH of ligand Lauric acid with metal ionsMn(II), $\mathrm{Co}(\mathrm{II}), \mathrm{Ni}(\mathrm{II}), \mathrm{Cu}(\mathrm{II})$ and $\mathrm{Zn}$ (II) $50 \%$ (v/v) DMSO$\mathbf{5 0} \%(\mathrm{v} / \mathrm{v})$ water system 
Table 3: Metal-ligand stability constants of Lauric acid with transition metal ions in 50\%(v/v) DMSO-50\%(v/v) water system

\begin{tabular}{lcccc}
\hline System & $\log \mathrm{K}_{1}$ & $\log \mathrm{K}_{2}$ & $\log \mathrm{K}_{1}-\log \mathrm{K}_{2}$ & $\log \mathrm{K}_{1} / \log \mathrm{K}_{2}$ \\
\hline $\mathrm{Mn}(\mathrm{II})-\mathrm{L}$ & 3.097 & 2.610 & 0.487 & 1.187 \\
$\mathrm{Co}(\mathrm{II})-\mathrm{L}$ & 3.077 & 2.520 & 0.557 & 1.221 \\
$\mathrm{Ni}(\mathrm{II})-\mathrm{L}$ & 3.087 & 2.620 & 0.467 & 1.178 \\
$\mathrm{Cu}(\mathrm{II})-\mathrm{L}$ & 2.997 & 2.600 & 0.397 & 1.153 \\
Zn (II) - L & 3.067 & 2.500 & 0.567 & 1.227 \\
\hline
\end{tabular}

\section{DISCUSSION}

The present work explains the complexation of selective divalent transition metal ions with lauric acid in the aqueous-DMSO medium. The dissociation and stability constants have been determined to understand the behavior of the ligand and its interaction with metal ions in the aqueousDMSO medium. The ligand was a weak complexing agent. The change in color (without precipitation) concerning $\mathrm{pH}$ value of solution and deviation of ligand curve from metal ion curve also shows the commencement of complex formation.

The difference between $\log \mathrm{K}_{1}$ and $\log \mathrm{K}_{2}$ values signifies the formation of complexes. Since the difference between $\log \mathrm{K}_{1}$ and $\log \mathrm{K}_{2}$ is small,both $1: 1$ and 1:2 complexes are formed simultaneously and but not in a stepwise manner. On adding DMSO to water as co-solvent, there is a decrease in the dielectric constant of the solvent medium and the interaction among solvent molecules are found to be increased ${ }^{12}$.

The less value of dielectric constant is the reason for the lowering in solvation of the metal ions in DMSO, resulting in higher attraction force which in turn, approaches the ligand to viable coordination of metal ion resulting in enhanced stability of the complex in $\mathrm{DMSO}^{13}$, hence the electrostatic forces of attraction between two oppositely charged species were significant, and therefore the stability of the complexes are more in the aqueous-organic solvent mixtures than in purely aqueous medium. This could be attributed to the hydrogen bonding ability of water and the solvating tendency of $\mathrm{DMSO}^{14}$. The higher value of the ratio $\left(\log \mathrm{K}_{1} / \log \mathrm{K}_{2}\right)$ for $\mathrm{Co}(\mathrm{II})$ and $\mathrm{Zn}(\mathrm{II})$ ligand complexes denotes the stability of the above complexes is more compared to $\mathrm{Mn}(\mathrm{II}), \mathrm{Ni}(\mathrm{II})$ and $\mathrm{Cu}(\mathrm{II})$-ligand complexes.

\section{CONCLUSION}

The dissociation constant of lauric acid and stability constants of lauric acid-metal complexes in the binary solvent medium could be important information for biochemists. This study helps to understand the metal-ligand interactions in aqueous-organic solvent mixtures and could be quite informative for the study of the pharmaceutical applications of lauric acid in the future.

\section{ACKNOWLEDGMENT}

The authors wish to thank the Head and faculty of the Department of Chemistry, D.G.Vaishnav for their support in carrying out this work.

\section{REFERENCES}

1. Belay,H.H.;Sailaja,B.B.V.; Rao,G.N.Der Pharma Chemica., 2015, 7(5),147-156.

2. Beare-Rogers,J.;Dieffenbacher,A.;Holm,J.V.Pure and Applied Chemistry., 2001, 73(4),685-744.

3. Nakatsuji,T.;Kao,M.C.;Fang,J.Y.;Zoubilis,C.C.; Z hang,L.;Gallo,R.L.;Huang,C.M. The Journal of Investigative Dermatology., 2009, 129(10), 2480-8

4. HarminderKaur;AnitaSingla. International Journal of Pure \&Applied Chemistry., 2011, 6,149-153.

5. Tayade,D.T.;Wadekar,A.B.;International Journal of Applied Research., 2015, 01, 640-642.

6. Hussain. Chemistry Journal., 2012, 02, 206-209.

7. Abdalazeem,A.O.;Elmugdad.A.International Journal Of Advanced Chemistry., 2015, 03, 6-13.
8. Avinash Ramteke; Marutil Narwade. Archives of Applied Science Research., 2013, 5, 231-237.

9. Vijayarohini,P.; Kavitha,G.;Bangaru Sudarsan Alwar, S. Der Pharma Chemica., 2017, 9(22), 25-28.

10. Rahman,M.A.;Ghosh,A.K.;Bose,N.A. Journal of Chemical Technology and Biotechnology., 1979, 29,158-162.

11. Irving,H.M.; Rossetti, H. S. Journal of Chemical Society., 1954, 2904.

12. Srinivas, N.; Manikyamba, P. Rasayan Journal of Chemistry., 2008, 1, 315-321.

13. Thanavelan,R.; Ramalingam,G.; Manikandan, G.; Thanikachalam,V. Journal of Saudi Chemical Society., 2014,18, 227-233.

14. Vijaykumar,S.I.; Ashwini,K.S. Polyhedron., 2003, 22, 569-574. 